\title{
Ultrasound-assisted oxidative-adsorptive desulfurization using highly acidic graphene oxide as a catalyst-adsorbent
}

\author{
G. Abdi ${ }^{1}$, M. Ashokkumar ${ }^{2}$ and A. Alizadeh ${ }^{1,3^{*}}$
}

\footnotetext{
${ }^{1}$ Department of Organic Chemistry, Faculty of Chemistry, Razi University, Kermanshah 6714967346, Iran

${ }^{2}$ School of Chemistry, University of Melbourne, VIC 3010, Australia

${ }^{3}$ Nanoscience \& Nanotechnology Research Center (NNRC), Razi University, Kermanshah, Iran
}

\begin{abstract}
Modified graphene oxide by acetic acid moiety $(\mathrm{GO} / \mathrm{COOH})$ was synthesized and employed in the ultrasoundassisted oxidative-adsorptive desulfurization processes. The modified graphene oxide was characterized by scanning electron microscopy (SEM), transmission electron microscopy (TEM), Fourier transform infrared (FTIR) spectroscopy, X-ray photoelectron spectroscopy (XPS), and Raman spectroscopy The fabricated material was applied to simultaneous oxidation and adsorption of dibenzothiophene (DBT) from model fuel. Adsorption studies were carried out to evaluate its potential for DBT removal. The effects of contact time, initial DBT concentration, and temperature on the removal efficiency of the catalyst-adsorbent were investigated. The equilibrium adsorption results was well-described by the Freundlich isotherm model (at room temperature) and oxidation-adsorption of DBT were achieved by $\mathrm{GO} / \mathrm{COOH}$ with an outstanding adsorption capacity of $370 \mathrm{mg}$ $\mathrm{g}-1$. The adsorption process followed a pseudo-first-order kinetic model and the adsorption kinetic data suggests that physical interactions are mainly involved on the entire adsorption process $(\mathrm{Ea}<40 \mathrm{~kJ}$ mol-1). The initial sulfur content of $1000 \mathrm{ppm}$ was reduced to $<50 \mathrm{ppm}$ within $300 \mathrm{~min}$, achieving a sulfur removal of about $95 \%$. As a whole, a model fuel with ultra-low sulfur content was obtained by the developed procedure and $\mathrm{GO} / \mathrm{COOH}$ shows a high potential for effective desulfurization of diesel fuel as a catalyst-adsorbent.
\end{abstract}

Keywords: Catalyst-adsorbent materials, Oxidative-adsorptive desulfurization, Dibenzothiophene, Modified-graphene oxide. 